\title{
Organizational Culture, Leadership Behaviors, and Employee Attitude in Chinese SMEs: Empirical Evidence
}

\author{
Yu Liu \\ Kyushu University, Fukuoka, Japan
}

\begin{abstract}
This study examines the impact of organizational culture on leadership behaviors, as well as the influence of leadership behaviors on employee attitude in Chinese small and medium-sized enterprises (SMEs). Based on previous researches, this study establishes a conceptual model that indicates the two types of influential relationship. Data are collected from 515 subordinates of 23 SMEs in Chengdu of Sichuan province. By using statistical methods, findings of this study are concluded. Directions for future research are also discussed.
\end{abstract}

Keywords: organizational culture, leadership behavior, employee attitude, SMEs

\section{Introduction}

During the last three decades, Chinese economy has experienced a prolonged transition from centrally planned economy to socialist market economy. In the transition period, the nation's politics, economy, and culture have been greatly changed, while the most attractive one is that Chinese small and medium-sized enterprises (SMEs) have drastically flourished. Till now, it has already become the vital factor for the rapid development of the Chinese economy. In 2008, the number of Chinese SMEs rose up to 42.8 million which accounts for 99.25 percent of all enterprises. Till 2009, SMEs in China had employed around 78 percent of workforce. SMEs exports amounted to 68.65 percent of total exports in China in 2006.

As to the reasons underlying the flourish of Chinese SMEs, two main factors can be concluded. One is the upgrading of human resources in both quantity and quality in China. Another one is the most important role that entrepreneurs play in the development of Chinese SMEs. In detail, China has over 1.37 billion people, of which around 800 million are economically active populations (NBS, 2010). The largest population foundation in the world provides adequate labor force for the growth of Chinese SMEs. In addition, the fast development of Chinese higher education and vocational education, furthermore, overseas-educated Chinese dramatically swarming into Chinese labor market have remarkably enhanced the quality of human resources in China. The great changes in both quantity and quality of Chinese human resources bring challenges to human resource management. Especially, this change has attracted much emphasis on the effectiveness of entrepreneurs in Chinese SMEs, because it has been practically and academically proven that entrepreneurs connect crucially with the destiny of SMEs.

Since human resources and entrepreneurs have been considered to be the most significant factors for the flourish of Chinese SMEs, it is important to make clear that how entrepreneurs lead the employees to improve

Yu Liu, Ph.D., Graduate School of Economics, Kyushu University.

Correspondence concerning this article should be addressed to Yu Liu, 6-19-1 Hakozaki, Higashi-ku Fukuoka 812-8581, Japan. E-mail: liuyuscu@163.com. 
their organizations. Hence, the purpose of this research is to probe the impact of organizational culture on leadership behaviors and the influence of leadership behaviors on employee attitude. The expected achievement of this research is to help entrepreneurs taking feasible and effective leadership behaviors to stimulate active employee attitude under different organizational culture.

\section{Relevant Literatures and Research Models}

Although there is still no general consensus on the definition of organizational culture, one frequently cited definition is from Schein (1992), who defined organizational culture as:

The pattern of basic assumptions that a given group has invented, discovered, or developed in learning to cope with its problems of external adaptation and internal integration, and that have worked well enough to be considered valid, and, therefore, to be taught to new members as the correct way to perceive, think, and feel in relation to other problems. (p. 12)

Definition of organizational culture from Lau and Ngo (1996) is also generally acknowledged. They defined an organization's culture as a common understanding and things including philosophies, ideologies, values, assumptions, expectations, perceptions, norms, sayings, behaviors, heroes, and traditions that are shared among members of the organization (Lau \& Ngo, 1996).

As to the way of classifying organizational culture, Competing Values Framework (CVF) is deemed as one of the most influential and widely used models in organizational culture research. CVF categorizes four types of organizational culture (group, developmental, hierarchical, and rational culture) from two dimensions (flexibility vs. control orientation and within vs. outside the organization orientation) (Denison \& Spreitzer, 1991). In detail, group culture emphasizes flexibility and maintains a primary focus on the internal organization. This kind of organizational culture is full of atmosphere of openness and emphasizes the morale of employees. As to developmental culture, innovation and adaptation are strongly emphasized to glue the organization together. Growth is the eternal goal for organizations with developmental culture. Hierarchical culture has clear structures, strict rules, and well defined responsibilities which are regarded as the glues that hold the organization together. Rational culture stresses on goal achieving, so the accomplishment of tasks and goals is the prime criteria of success. The chasing of profit and productivity is the significant orientation for the organization with rational culture.

Based on this framework, many empirical studies (Lau \& Ngo, 1996; Quinn \& Spreitzer, 1991) have testified the impact of organizational culture on individuals' perceptions and behaviors. But most studies concentrated on individuals' reflection to organizational culture at the level of employees, while the leaders' behaviors were hardly emphasized when considering the impact of organizational culture on individual behaviors.

In leadership theories, transformational and transactional leadership are classic and representative. Burns (1978) is the first scholar who introduced the concepts of transactional and transformational leadership in his descriptive research. According to Burns (1978), transformational leaders inspire the followers to do more than what the contract requires by paying attention to their personal development, while transactional leaders motivate employees through offering rewards and punishments according to their accomplishment of goals.

Another scholar, Bass (1985) developed transactional and transformational leadership theories. According to Bass (1985), entrepreneurs of transactional type are prone to clarify the criteria of rewards and punishments on the basis of organizational goals to form the relationship of benefit exchange between leaders and employees. Transformational leaders encourage followers to resolve problems in new and creative ways and focus on employees' difference and personal needs to improve the morale. 
Paternalistic leadership as a management concept with oriental characteristics can be traced back to the early works of Max Weber. According to Weber (1947), paternalism is defined as one form of legitimated authority and one of the most elementary types of traditional domination. More recent researches from Middle East, Pacific Asia, and Latin America (Farh, Cheng, Chou, \& Chu, 2006; Martinez, 2003; Pellegrini \& Scandura, 2006; Uhl-Bien, Tierney, Graen, \& Wakabayashi, 1990) have proven that paternalism is still a prevalent and effective leadership style in many business cultures. Westwood (1997) suggested that paternalistic leadership is effective in the Chinese business context because it matches properly with the core value of Chinese traditional culture-compliance and harmony. Farh and Cheng (2000) argued that paternalistic leadership has positive implications in oriental society, because almost all Asian countries and districts are intensively affected by oriental cultures like Confucianism and Taoism that are the indigenous cultural context for the origination of paternalistic leadership.

As to employee attitude, many variables have been applied to measure it directly or indirectly. The most representative variables are job satisfaction, turnover intention, and work effort. Job satisfaction is an intuitive concept that reflects employees' perception of the value or interest of work itself, rewards, relationship among peers, and appraisals from leaders and organization (Broome, Knight, Edwards, \& Flynn, 2009). At the level of organizations and managers, job satisfaction can directly reflect employees' performance, for it usually links to job-related behaviors. Employees with turnover intention will directly affect their performance, even that of organizations (Schwepker, 2001). Bluedorn (1982) reported that turnover intention has a positive impact on actual leaving behavior which is significantly related to the individual's performance. Effort is one of the most significant constructs in motivation theory. It can be conceptualized as the energy that people put into their behaviors (Mohr \& Bitner, 1995).

As to the relationship between organizational culture and leadership behaviors, Song and Zhu (2003) argued that organizations have different requirement on leadership under different organizational culture on the basis of leadership theory. As to leader effectiveness, transformational leadership has been proven to be effective in increasing followers' job satisfaction (Mirkamali, Thani, \& Alami, 2011), organizational citizenship behaviors (Nahum-Shani \& Somech, 2011), organizational identification (Epitropaki \& Martin, 2005), and service performance (Liao \& Chuang, 2007). But transactional leadership is less positively related with followers' effectiveness compared to transformational leadership (Wofford \& Goodwin, 1994). Paternalistic leadership has been proven to be effective in organizations with high power distance, according to Saufi, Wafa, and Hamzah (2002). On the basis of literature review, the conceptual model can be established in Figure 1.

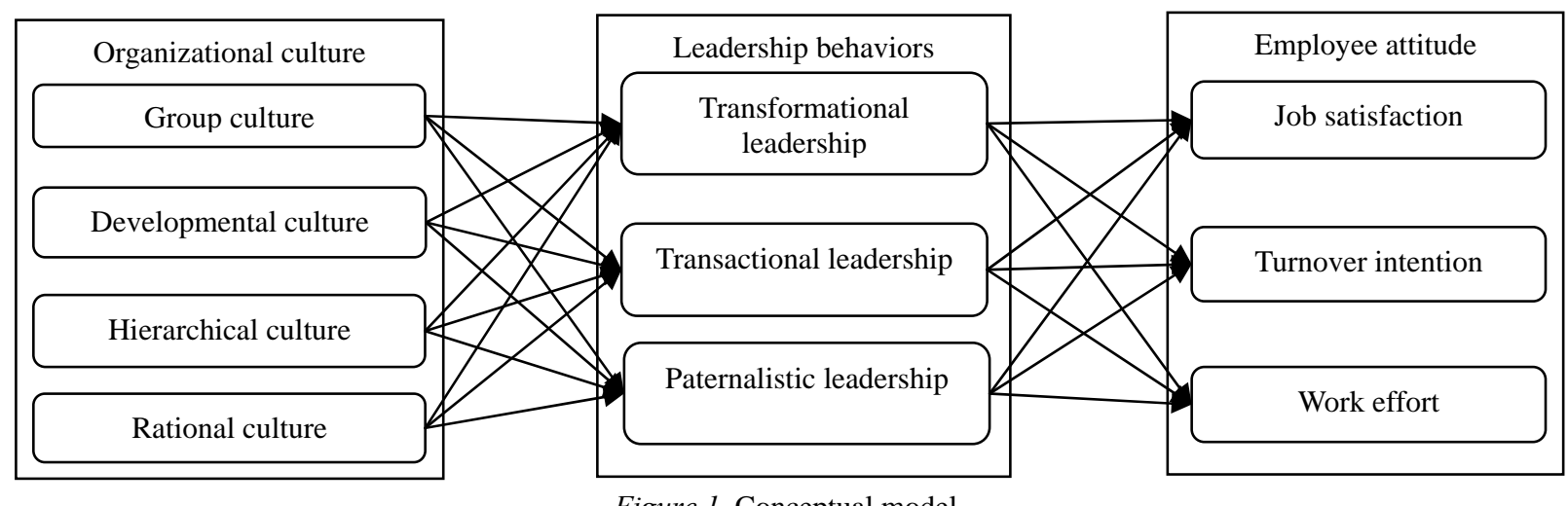

Figure 1. Conceptual model. 


\section{Model Testify}

\section{Data Resource}

The survey was carried out in Wuhou high-tech industrial development zone of Sichuan province in China. It was established in 2000, with a planned area of 3.5 square kilometers. Till the year of 2006, the zone had achieved accumulated 8.3 billion RMB of industrial output. There are over 300 high-tech enterprises in the zone and they account for more than $90 \%$ of the total industrial output. The leading industries in Wuhou high-tech industrial development zone are electronic information, mechanical and electrical industry, biological medicine, and new materials.

This research defines Chinese SMEs as enterprises with less than 500 employees, taking no account of their capital scale, industry, pattern of ownership etc.. The reasons are: First, the definition of Chinese SMEs is complex and it has experienced great changes in the last few decades. Second, the various standards for categorizing Chinese SMEs have further increased the difficulty of understanding this concept and even the research concerning about Chinese SMEs.

Two main selecting methods were used for sampling. They are random selection and random walking. The list of SMEs was offered by the administration committee of Wuhou high-tech industrial development zone at first. Then the sample firms were selected out by using the method of random selection. In addition, the subordinates who will be asked to accomplish the questionnaires were selected out from the employee list of sample firms also by random selection. However, all the employees of the firms with less than 10 headcounts were required to finish questionnaires. For those SMEs which are not on the firm list, the method of random walking was used.

By using the methods introduced above, 23 SMEs were selected out to be sample firms. These firms belong to the industries of manufacturing, telecommunication, environment protection, transportation, and logistics. All the sample firms are of state-owned enterprises, private companies, and joint venture. The leadership style of 23 top leaders of these SMEs will be judged by their subordinates. Seven hundred employees were also selected out as participants to complete all parts of the questionnaire. The researcher initially distributed 700 questionnaires to the 23 SMEs, and 515 completed and useable questionnaires were received, indicating an overall response rate of $73.6 \%$.

\section{Survey Design}

In statistical survey, common method bias is a kind of systematic error variance shared among variables. The spurious variance can be attributed to reasons from questionnaire, samples, and survey design. Based on the remedies proposed by Podsakoff, MacKenzie, and Podsakoff (2012), common method bias has been minimized in this research.

First, in order to extremely alleviate the factors from a questionnaire that will cause the common method bias, this research took some effective measures on questionnaire designing. In detail, these obvious ways are: simplify complex or compound questions; translate questionnaire between Chinese and English twice in order to use vocabulary and syntax that match with the reading custom of the participants; define ambiguous terms in the questionnaire; split double-barreled questions up into two questions; group related items together and divide the questionnaire into three parts.

Second, for resolving the bias problem caused from respondents, all the sample firms were selected out from Wuhou high-tech industrial development zone. Over 96\% of respondents in these sample firms have 
educational background above high school and over $90 \%$ of them have already work for the firm for over one year. Hence, they have the quality of reading skills, education, or cognitive sophistication to understand issues in the questionnaire and the working experience to easier their understanding about the topics of the survey. Meanwhile, information for survey and cover letter of the questionnaire particularly stressed the purpose of survey, voluntary, confidentiality, feedback, expected benefits, and appreciation for participation, so as to increase the willingness of respondents to answer questions according to their own perceptions.

Third, survey design is the key procedure to diminish the common method bias problem. This research divided the questionnaire into three parts. Part one refers to organizational culture, while part two and three concern about leadership and employee attitude. So part one was separated from part two and three when taking field survey. The time and space of taking questionnaire of different parts are different and artificially separated in order to alleviate the bias caused by environment factors.

\section{Measures}

Organizational culture. Items for organizational culture were adapted from Lau and Ngo (1996), consisting of 16 items on four dimensions at the values and assumptions level as suggested by the competing values framework: group culture (four items), developmental culture (four items), hierarchical culture (four items), and rational culture (four items). The Cronbach's alpha coefficients of group culture, developmental culture, hierarchical culture, and rational culture were $0.762,0.842,0.832$, and 0.796 , respectively.

Leadership behaviors. Transactional and transformational leadership behavior will be operationalized using Multifactor Leadership Questionnaire (MLQ) from Bass and Avolio (1996). In this research, the rater forms are chosen as the measure instrument. The rater form consists of 32 questions. Paternalistic leadership behavior is going to be measured by using a questionnaire developed by Cheng, Chou, and Farh (2000). Paternalistic leadership has three distinct elements: authoritarian leadership, benevolent leadership, and moral leadership. They were measured with 26 items using a five-point Likert scale. The Cronbach's alpha coefficients of transactional, transformational, and paternalistic leadership were $0.869,0.953$, and 0.868 , respectively.

Employee attitude. Job satisfaction was measured by using a global indicator developed by Cammann, Fichman, Jenkins, and Klesh (1979) (in MacIntosh \& Doherty, 2010). This paper will use Kelloway, Gottlieb, and Barham's (1999) four-item measure to assess respondents' turnover intention. In addition, this research will measure work effort by using the three-item scale developed by Brockner, Grover, Reed, and Dewwitt (1992). The Cronbach's alpha coefficients of job satisfaction, turnover intention, and work effort were $0.788,0.908$, and 0.900 , respectively.

Control variables. As to the impact of organizational culture on leadership behaviors, gender, age, and educational experience of entrepreneurs were found to directly influence entrepreneur's behavior in prior research. When considering the impact of leadership behaviors on employee attitude, employees' gender, age, educational experience, tenure, and position will be introduced. But the impact of these individual factors on leadership behaviors and employee attitude is not the main problem that will be discussed in this research. They will only be introduced as control variables. Gender was dummy coded ( $1=$ male, 2 = female). Five-item variables were used to measure age from $1=20-30$ years to $5=60$ years above. Six-item variables were used to measure educational experience with $1=$ junior middle school, $4=$ bachelor's degree, and $6=$ others. Tenure and position will be measured by five and seven blocks respectively. 


\section{Methods}

The measures will be subjected to reliability analysis by using SPSS to examine the reliability of questionnaires. The validity of measures has already been tested by prior researches, because all the questionnaires are classic and oft-applied. Hence, the validity test of questionnaires will not be taken in this research. The measures will also be subjected to correlation analysis in order to reveal the correlative relationship between variables in order to modify the conceptual model. Regression analysis is conducted to test the causal relationships between variables.

\section{Results}

Since the personal characteristics of individuals, like gender, age, educational experience, tenure, and position influence on individual behaviors, the impact of gender, age, and educational experience on the choice of leadership behaviors will be first examined. As can be seen from Table 1, entrepreneurs' gender significantly is related to transformational and transactional leadership, but does not significantly influence on the choice of paternalistic leadership at the level of 0.05 . The factor of age insignificantly impacts on the three types of leadership. Educational experience is significantly related to transformational leadership at the level of 0.05 , while it is insignificantly related to transactional and paternalistic leadership. Therefore, the variables of entrepreneurs' gender and educational experience will be introduced in correlation analysis.

Table 1

ANOVA

\begin{tabular}{lllllll}
\hline \multirow{2}{*}{ Dependent variables } & \multicolumn{2}{c}{ Gender } & \multicolumn{2}{c}{ Age } & \multicolumn{3}{c}{ Educational experience } \\
& $F$ & Sig. & $F$ & Sig. & $F$ & Sig. \\
\hline Transformational leadership & 17.272 & 0.000 & 0.579 & 0.447 & 3.063 & 0.028 \\
Transactional leadership & 7.821 & 0.005 & 2.616 & 0.106 & 0.712 & 0.545 \\
Paternalistic leadership & 2.671 & 0.103 & 0.003 & 0.960 & 0.345 & 0.793 \\
\hline
\end{tabular}

Note. The impact of entrepreneurs' gender, age, and educational experiences on the three types of leadership.

From Table 2, the employees' gender, educational experience, and position impact on job satisfaction, turnover intention, and work effort insignificantly at the level of 0.05 . As to the factor of age, it is significantly related to job satisfaction and turnover intention, but not significantly related to work effort at the level of 0.05 . Tenure has a significant influence on turnover intention and work effort, but is not significantly related to job satisfaction. Hence, the variables of employees' age and tenure will be introduced in the next correlation analysis.

Table 2

ANOVA

\begin{tabular}{llllllllllll}
\hline \multirow{2}{*}{ Dependent variables } & \multicolumn{2}{c}{ Gender } & \multicolumn{2}{c}{ Age } & \multicolumn{3}{c}{ Educational experience } & \multicolumn{2}{c}{ Tenure } & \multicolumn{2}{c}{ Position } \\
& $F$ & Sig. & $F$ & Sig. & $F$ & Sig. & $F$ & Sig. & $F$ & Sig. \\
\hline Job satisfaction & 0.020 & 0.887 & 2.709 & 0.030 & 1.616 & 0.154 & 1.951 & 0.101 & 0.497 & 0.811 \\
Turnover intention & 0.084 & 0.772 & 3.325 & 0.011 & 1.060 & 0.382 & 2.628 & 0.034 & 0.182 & 0.982 \\
Work effort & 2.532 & 0.112 & 1.183 & 0.317 & 0.213 & 0.957 & 3.952 & 0.004 & 0.202 & 0.976 \\
\hline
\end{tabular}

Note. The impact of employees' gender, age, educational experience, tenure, and position on job satisfaction, turnover intention, and work effort. 
Table 3

Means, Standard Deviations, and Correlations of the Variables $(N=515)$

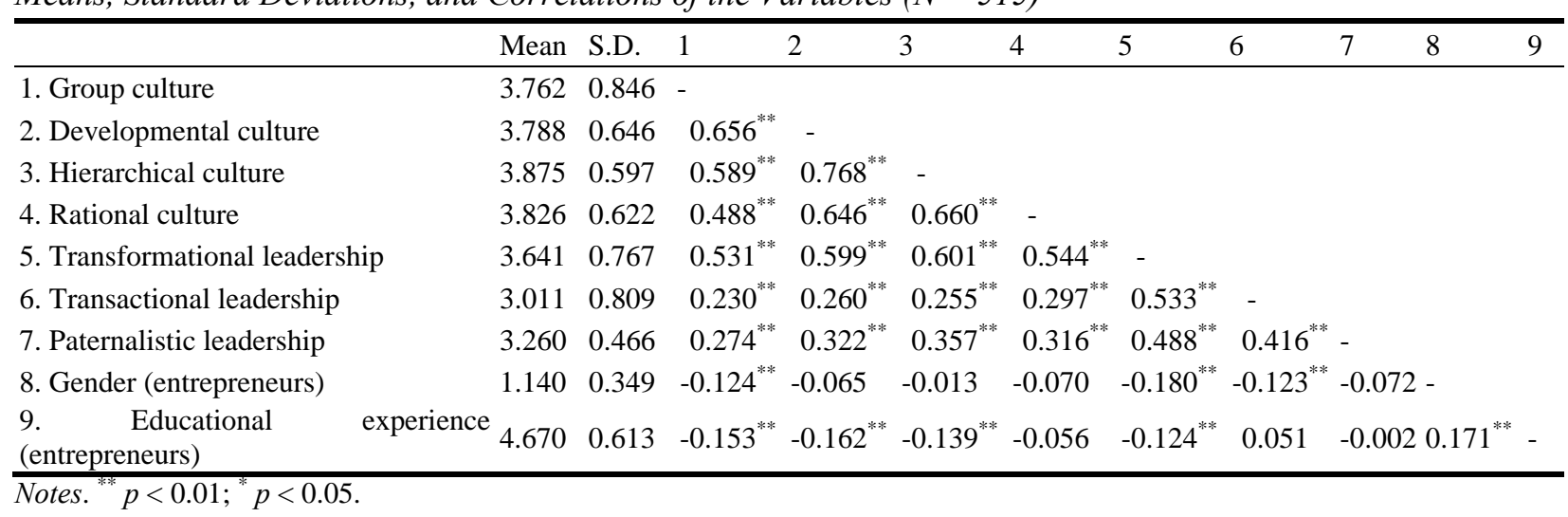

Table 4

Means, Standard Deviations, and Correlations of the Variables $(N=515)$

\begin{tabular}{lllllllllll}
\hline & Mean & S.D. & 1 & 2 & 3 & 4 & 5 & 6 & 7 & 8 \\
\hline 1. Transformational leadership & 3.641 & 0.767 & - & & & & & & & \\
2. Transactional leadership & 3.011 & 0.809 & $0.533^{* *}$ & - & & & & & \\
3. Paternalistic leadership & 3.260 & 0.466 & $0.488^{* *}$ & $0.416^{* *}$ & - & & & & \\
4. Job satisfaction & 3.531 & 0.743 & $0.425^{* *}$ & $0.112^{*}$ & $0.207^{* *}$ & - & & & \\
5. Turnover intention & 2.409 & 0.852 & $-0.332^{* *}$ & 0.058 & -0.059 & $-0.590^{* *}$ & - & & & \\
6. Work effort & 4.146 & 0.587 & $0.355^{* *}$ & $0.130^{* *}$ & $0.240^{* *}$ & $0.258^{* *}$ & $-0.286^{* *}$ & - & \\
7. Age (employee) & 1.740 & 0.843 & 0.081 & $0.087^{*}$ & 0.016 & $0.125^{* *}$ & $-0.105^{*}$ & 0.079 & - \\
8. Tenure (employee) & 3.370 & 1.355 & 0.029 & -0.016 & 0.049 & 0.065 & -0.074 & $0.103^{*}$ & $0.589^{* *}$ & - \\
\hline
\end{tabular}

Notes. ${ }^{* * *} p<0.01 ;{ }^{*} p<0.05$.

Tables 3 and 4 give the means, standard deviations, and correlations of the variables in this research. According to Table 3, the four types of organizational culture are significantly related to the three styles of leadership at the level of 0.05 . The entrepreneurs' gender has significant impact on transformational and transactional leadership, while entrepreneurs' educational experience has been significantly related to transformational leadership. In Table 4, the three types of leadership significantly impact on job satisfaction and work effort. Transformational leadership has negative impact on turnover intention at the level of 0.05 , while transactional and paternalistic leadership insignificantly impact on employees' turnover intention. Employees' age impacts significantly on job satisfaction and turnover intention, while tenure has a significant influence on work effort.

Results for the regression analysis are presented in Tables 5 and 6. According to Table 5, the impact of four types of organizational culture on transformational leadership is shown in Model 1 (see Table 5). The results indicate that group, developmental, hierarchical, and rational culture are positively related to transformational leadership with standardized coefficients $(\beta)$ of $0.166,0.176,0.253$, and 0.173 at the significant level of 0.01 . The control variable-gender also has a significant influence on transformational leadership.

Model 2 (see Table 5) represents the impact of four types of organizational culture on transactional leadership. Based on the results from Table 5, only rational culture has a positive impact on transactional leadership $(\beta=0.182, p<0.01)$. The impact of group, developmental and hierarchical culture on transactional 
leadership is not significant. However, entrepreneurs' gender and educational experience are significantly related to transactional leadership.

Model 3 (see Table 5) shows that the influence of group, developmental and rational culture on paternalistic leadership is not significant, while hierarchical culture is significantly related to paternalistic leadership ( $\beta=0.219, p<0.01$ ). The influence of gender and educational experience on leadership behaviors is not significant.

Table 5

Results of Regression Analysis for the Impact of Organizational Culture on Leadership Behaviors $(N=515)$

\begin{tabular}{lccc}
\hline & & Model & \\
Independent variable & 1 & 2 & 3 \\
& Beta & Beta & 0.063 \\
\hline Group culture & $0.166^{* *}$ & 0.067 & 0.048 \\
Developmental culture & $0.176^{* *}$ & 0.062 & $0.219^{* *}$ \\
Hierarchical culture & $0.253^{* *}$ & 0.062 & 0.109 \\
Rational culture & $0.173^{* *}$ & $0.182^{* *}$ & -0.061 \\
Gender (entrepreneur) & $-0.133^{* *}$ & $-0.116^{* *}$ & 0.063 \\
Educational experience (entrepreneur) & -0.003 & $0.110^{*}$ & 0.063
\end{tabular}

Notes. Model 1 dependent variable: Transformational leadership; Model 2 dependent variable: Transactional leadership; Model 3 dependent variable: Paternalistic leadership. ${ }^{* *} p<0.01 ;{ }^{*} p<0.05$.

Table 6 shows the regression results on the impact of leadership behaviors on employee attitude. In Model 1 (see Table 6), transformational leadership has a positive impact on job satisfaction $(\beta=0.490, p<0.01$ ), while transactional leadership negatively impacts on job satisfaction $(\beta=-0.176, p<0.01)$. The impact of paternalistic leadership on job satisfaction is not significant. However, the employees' age has a significant influence on job satisfaction at the level of 0.05 .

Model 2 (see Table 6) represents that transformational leadership has negative impact on turnover intention ( $\beta=-0.527, p<0.01$ ), while transactional leadership positively impacts on turnover intention $(\beta=0.318, p<0.01$ ). The impact of paternalistic leadership and employees' age and tenure on turnover intention is not significant.

Model 3 (see Table 6) shows that the influence of transformational and paternalistic culture on work effort is positive with standardized coefficients $(\beta)$ of 0.354 and 0.105 at the significant level of 0.01 and 0.05 , while transactional leadership is negatively related to work effort $(\beta=-0.102, p<0.05)$. However, the influence of control variables on work effort is not significant.

Table 6

Results of Regression Analysis for the Impact of Leadership Behaviors on Employee Attitude $(N=515)$

\begin{tabular}{llcc}
\hline & & Model & 3 \\
Independent variable & 1 & 2 & Beta \\
\hline Transformational leadership & Beta & Beta & $0.354^{* *}$ \\
Transactional leadership & $0.490^{* *}$ & $-0.527^{* *}$ & $-0.102^{*}$ \\
Paternalistic leadership & $-0.176^{* *}$ & $0.318^{* *}$ & $0.105^{*}$ \\
Age (employees) & 0.040 & 0.068 & 0.010 \\
Tenure (employees) & $0.112^{*}$ & -0.089 & 0.080 \\
\hline
\end{tabular}

Notes. Model 1 dependent variable: Job satisfaction; Model 2 dependent variable: Turnover intention; Model 3 dependent variable: Work effort. ${ }^{* *} p<0.01 ;{ }^{*} p<0.05$. 


\section{Discussion}

In this section, theoretical and practical implications will be discussed. In addition, suggestions for future research will be pointed out on the basis of limitations of this study.

\section{Theoretical Implications}

This study responds to the question of how organizational culture relates to leadership behaviors in Chinese SMEs. In other words, this contributes to a theoretical extension of the research on leadership by taking organizational culture as an antecedent of leadership behavior, which has not been sufficiently explored in the past.

The findings of the study show that the four types of organizational culture relate to different styles of leadership behaviors. According to the results, group, developmental, hierarchical, and rational culture has a positive influence on transformational leadership. This totally proves the evidence that transformational leadership matches properly with all kinds of organizational culture. Rational culture links positively to transactional leadership. Moreover, in SMEs of hierarchical culture, entrepreneurs are prone to take paternalistic leadership to establish leader-member relationship of the characteristics of parents and sons.

In addition, findings in this research also represent that transformational leadership has quite significant and positive effect on job satisfaction and work effort, while it has a negative influence on employees' turnover intention. This study provides evidence that transformational leadership has been viewed as a universally effective leadership behavior in Chinese SMEs. Meanwhile, transactional leadership shows a negative impact on job satisfaction and work effort, but it is significantly related to turnover intention. We can conclude that in Chinese SMEs, transactional leadership is not suitable for improving employee attitude. As far as paternalistic leadership is considered, it is positively related to work effort, but its impact on job satisfaction and turnover intention is not significant. The underlying cause might be that employees in Chinese SMEs have to devote lots of effort to their daily jobs in the context of authority and obedience.

\section{Practical Implications}

The results of the influence of organizational culture on the choice of leadership behaviors imply that establishing a multicultural environment in an organization is quite necessary to obtain desired outcomes. Many previous researches have proven that cultural styles coexist in one organization simultaneously. Overemphasizing any culture type may become dysfunctional and the strength of the quadrant may even become a weakness (Denison \& Spreitzer, 1991).

Moreover, the findings of the impact of leadership behavior on employee attitude imply that entrepreneurs should be mindful of two notions: The first is the importance of leadership behaviors for improving employee attitude; the second is how the three types of leadership behaviors impact on employee attitude. In this study, transformational leadership has been proven to be the most effective leadership behavior. Transactional leadership is often rebelled by most employees. Entrepreneurs should alter their leadership behaviors to be transformational style. In detail, entrepreneurs could improve employees' attitude by paying attention to their personal development, enlarging their individual needs, and stimulating their work intention for organizational goals, but not through constructing relationship of "give and take" between entrepreneurs and employees.

\section{Directions for Future Research}

Though many findings have been concluded in this research, there are still several limitations that need to 
be considered when undertaking research in the future.

First, the applicability and generalizability of organizational culture, leadership, and employee attitude theory in oriental society need to be further explored in the future. The investigation area should be extended, so that even comparative analysis on leader effectiveness can be conducted among countries or districts under oriental culture background.

Second, data collection was conducted only in Wuhou high-tech industrial development zone in Chengdu of Sichuan province. Although this zone is one of the most representative industrial development zones in China, data collected from more zones of some other provinces in China will firmly increase the reliability and persuasion of the research. Future research will intend to take investigation in SMEs of other provinces in China to enlarge the extent of cases.

Third, more variables of outcomes should also be introduced to testify the effectiveness of leadership. Furthermore, the outcomes of leadership do not need to be restricted at the level of only individuals, such as performance of employees and entrepreneurs. Performance at the level of organization is worthy of exploration as the outcomes of leader effectiveness.

\section{References}

Bass, B. M. (1985). Leadership and performance beyond expectations. New York: Free Press.

Bass, B. M., \& Avolio, B. J. (1996). Manual for the multifactor leadership questionnaire. Palo Alto, C.A.: Mind Garden.

Bluedorn, A. C. (1982). A unified model of turnover from organizations. Human Relations, 35, 135-153.

Brockner, J., Grover, S., Reed, T., \& Dewwitt, R. (1992). Layoffs, job insecurity, and survivors' work effort: Evidence of an inverted-U relationship. Academy of Management Journal, 35, 413-425.

Broome, K. M., Knight, D. K., Edwards, J. R., \& Flynn, P. M. (2009). Leadership, burnout, and job satisfaction in outpatient drug-free treatment programs. Journal of Substance Abuse Treatment, 37, 160-170.

Burns, J. M. (1978). Leadership. New York: Harper \& Row.

Cammann, C., Fichman, M., Jenkins, D., \& Klesh, J. (1979). The Michigan organizational assessment questionnaire (unpublished manuscript). University of Michigan.

Cheng, B. S., Chou, L. F., \& Farh, J. L. (2000). A triad model of paternalistic leadership: The constructs and measurement. Indigenous Psychological Research in Chinese Societies, 14, 3-64.

Denison, D. R., \& Spreitzer, G. M. (1991). Organizational culture and organizational development: A competing values approach. Research in Organizational Change and Development, 5, 1-21.

Epitropaki, O., \& Martin, R. (2005). The moderating role of individual differences in the relation between transformational/transactional leadership perceptions and organizational identification. Leadership Quarterly, 16, 569-589.

Farh, J. L., \& Cheng, B. S. (2000). A cultural analysis of paternalistic leadership in Chinese organizations. In J. T. Li., A. S. Tsui, \& E. Weldon (Eds.), Management and organizations in the Chinese context (pp. 84-127). London: Macmillan.

Farh, J. L., Cheng, B. S., Chou, L. F., \& Chu, X. P. (2006). Authority and benevolence: Employees' responses to paternalistic leadership in China. In A. S. Tsui, Y. Bian, \& L. Cheng (Eds.), China's domestic private firms: Multidisciplinary perspectives on management and performance (pp. 230-260). New York: Sharpe.

Kelloway, E. K., Gottlieb, B. H., \& Barham, L. (1999). The source, nature, and direction of work and family conflict: A longitudinal investigation. Journal of Occupational Health Psychology, 4, 337-346.

Lau, C. M., \& Ngo, H. Y. (1996). One country many cultures: Organizational cultures of firms of different country origins. International Business Review, 5, 469-486.

Liao, H., \& Chuang, A. (2007). Transforming service employees and climate: A multilevel, multisource examination of transformational leadership in building long term service relationships. Journal of Applied Psychology, 92, 1006-1019.

MacIntosh, E. W., \& Doherty, A. (2010). The influence of organizational culture on job satisfaction and intention to leave. Sport Management Review, 13, 106-117.

Martinez, P. G. (2003). Paternalism as a positive form of leader-subordinate exchange: Evidence from Mexico. Journal of Iberoamerican Academy of Management, 1, 227-242. 
Mirkamali, S. M., Thani, F. N., \& Alami, F. (2011). Examining the role of transformational leadership and job satisfaction in the organizational learning of an automotive manufacturing company. Social and Behavioral Sciences, 29, 139-148.

Mohr, L. A., \& Bitner, M. J. (1995). The role of employee effort in satisfaction with service transactions. Journal of Business Research, 32, 239-252.

Nahum-Shani, I., \& Somech, A. (2011). Leadership, OCB and individual differences: Idiocentrism and allocentrism as moderators of the relationship between transformational and transactional leadership and OCB. Leadership Quarterly, 22, 353-366.

National Bureau of Statistics (NBS) of China. (2010). China statistical yearbook. Beijing: State Statistics Bureau Press.

Pellegrini, E. K., \& Scandura, T. A. (2006). Leader-member exchange (LMX), paternalism and delegation in the Turkish business culture: An empirical investigation. Journal of International Business Studies, 37(2), 264-279.

Podsakoff, P. M., MacKenzie, S. B., \& Podsakoff, N. P. (2012). Sources of method bias in social science research and recommendations on how to control it. Annual Review of Psychology, 63, 539-569.

Quinn, R. E., \& Spreitzer, G. M. (1991). The psychometrics of the competing values culture instrument and an analysis of the impact of organizational culture on quality of life. In R. W. Woodman, \& W. A. Pasmore (Eds.), Research in organizational change and development (pp. 115-142). Greenwich, C.T.: JAI Press.

Saufi, R. A., Wafa, S. A., \& Hamzah, Y. Z. (2002). Leadership style preference of Malaysian managers. Malaysian Management Review, 37, 1-10.

Schein, E. H. (1992). Organizational culture and leadership: A dynamic view (2nd ed.). San Francisco: Jossey-Bass.

Schwepker, C. H. (2001). Ethical climate's relationship to job satisfaction, organizational commitment, and turnover intention in the salesforce. Journal of Business Research, 54, 39-52.

Song, H. Y., \& Zhu, D. (2003). A study of the leaders' traits influencing performance under different organizational culture. Journal of Xidian University, 13, 50-56.

Uhl-Bien, M., Tierney, P., Graen, G., \& Wakabayashi, M. (1990). Company paternalism and the hidden investment process: Identification of the "right type" for line managers in leading Japanese organizations. Group and Organization Studies, 15 , 414-430.

Weber, M. (1947). The theory of social and economic organization. New York: Free Press.

Westwood, R. (1997). Harmony and patriarchy: The cultural basis for "paternalistic headship" among the overseas Chinese. Organization Studies, 18, 445-480.

Wofford, J. C., \& Goodwin, V. L. (1994). A cognitive interpretation of transactional and transformational leadership theories. Leadership Quarterly, 5, 161-186. 